\title{
Evaluation of Flexural and Impact Strength of CAD-CAM and Two Different Conventional Denture Base Resins: An In Vitro Study
}

\author{
Ajinkya S Kirad ${ }^{1}$, Ramandeep Dugal ${ }^{2}$, Aamir Z Godil ${ }^{3}$, Arshi I Kazi ${ }^{4}$, Pallavi Madanshetty ${ }^{5}$, Taha Attarwala ${ }^{6}$
}

\begin{abstract}
Aim: To carry out a comparative evaluation of flexural strength and impact strength of computer-aided design/computer-aided manufacturing (CAD/CAM) denture base resin with conventional heat cure resin fabricated by two different techniques.

Materials and methods: The study was carried out in three groups based on the manufacturing process of the dentures: Group I ( $n=30$ ) —control group containing specimens fabricated by conventional pressure-pack technique (polymer and monomer-powder and liquid, (DPI, Mumbai, India)); Group II ( $n=30$ )_specimens fabricated using injection molding technique (SR_Ivocap High Impact, Ivoclar Vivadent, Liechtenstein); and Group III ( $n=30$ ) - specimens fabricated using CAD/CAM technology (Bloomden ${ }^{\mathrm{TM}}$, China). The values for flexural strength of each specimen were measured using a universal testing machine by a three-point bending test. Impact strength testing of the samples was done on the Izod impact testing machine with a pendulum of S2 scale in air at $23 \pm 2^{\circ} \mathrm{C}$. The mean values of the flexural strength and impact strength were calculated by the one-way ANOVA test and intergroup comparison was done using Tukey pairwise comparisons.

Results: The flexural strength (FS) and impact strength (IS) of CAD/CAM (FS $=93.16 \pm 5.46 \mathrm{MPa}$ and IS $=15.625 \pm 2.512 \mathrm{~kJ} / \mathrm{m}^{2}$ ) samples were highest followed by injection molded samples ( $\mathrm{FS}=84.82 \pm 5.30 \mathrm{MPa}$ and IS $=12.511 \pm 2.908 \mathrm{~kJ} / \mathrm{m}^{2}$ ) and least for compression molded control group ( $\mathrm{FS}=74.70 \pm 5.02 \mathrm{MPa}$ and $\mathrm{IS}=8.446 \pm 0.937 \mathrm{~kJ} / \mathrm{m}^{2}$ ).

Conclusion: CAD/CAM denture base resins have the highest flexural and impact strength compared to injection molded and compression molded heat cure denture base resins.

Keywords: CAD-CAM, Denture base resins, Flexural strength, Impact strength, Injection molding.

International Journal of Prosthodontics and Restorative Dentistry (2020): 10.5005/jp-journals-10019-1271
\end{abstract}

\section{INTRODUCTION}

Complete denture $(C D)$ rehabilitation is the most conventional and accepted form of prosthodontic treatment for patients with edentulism. An ideal denture base material should be biocompatible and have acceptable physical and mechanical properties. It should also be easy to clean and repair and allow optimal adhesion to denture teeth. ${ }^{1}$ Polymethyl methacrylate (PMMA) is currently the material of choice for denture fabrication. It was first introduced in 1937 by Dr Walter Wright and continues to be a popular material owing to its favorable working characteristics. ${ }^{2}$ Despite excellent properties, there is a need for improvement in the fracture resistance of PMMA. ${ }^{3}$

Flexural fatigue and impact forces may result in denture fractures, which is a common matter of concern to many denture wearers. As the alveolar ridge irregularly resorbs, the denture base has to endure uneven force distribution hence high flexural strength is critical. ${ }^{4}$ Fracture due to flexural fatigue is usually explained by the development of microscopic cracks in a stress concentration area. This type of fracture occurs over time and is not due to a single application of force like a fracture due to impact. The higher flexural strength of an acrylic resin ensures superior fracture resistance property, thereby making it less prone to clinical failure. ${ }^{5}$ Impact strength is a measure of the energy absorbed by a material when a sudden blow strikes it. Ideally, the denture base should have a sufficiently high impact strength to prevent breakage on accidental
1-4,6 Department of Prosthodontics, MA Rangoonwala College of Dental Sciences and Research Centre, Pune, Maharashtra, India

${ }^{5}$ Department of Prosthodontics, Rural Dental College, Pravara Medical Trust, Pravara Institute of Medical Sciences, Loni, Maharashtra, India

Corresponding Author: Arshi I Kazi, Department of Prosthodontics, MA Rangoonwala College of Dental Sciences and Research Centre, Pune, Maharashtra, India, Phone: +91 9619800927, e-mail: arshikazi2794@ gmail.com

How to cite this article: Kirad AS, Dugal R, Godil AZ, et al. Evaluation of Flexural and Impact Strength of CAD-CAM and Two Different Conventional Denture Base Resins: An In Vitro Study. Int J Prosthodont Restor Dent 2020;10(2):72-76.

Source of support: Nil

Conflict of interest: None

dropping. The processing technique used to polymerize the denture base resin has been found to be an important factor in determining the impact strength. ${ }^{6}$ Failure due to flexural fatigue may occur due to heavy occlusal biting forces. Failure may also occur as an outcome of impact force caused by accidentally dropping the denture. Therefore, testing the transverse strength and the impact strength of denture base materials have been used as a method of comparing their performance. ${ }^{7}$

The conventional dentures produced with compression molding technique shrink and distort. Porosity is also one of the

(O) The Author(s). 2020 Open Access This article is distributed under the terms of the Creative Commons Attribution 4.0 International License (https://creativecommons. org/licenses/by-nc/4.0/), which permits unrestricted use, distribution, and non-commercial reproduction in any medium, provided you give appropriate credit to the original author(s) and the source, provide a link to the Creative Commons license, and indicate if changes were made. The Creative Commons Public Domain Dedication waiver (http://creativecommons.org/publicdomain/zero/1.0/) applies to the data made available in this article, unless otherwise stated. 
undesirable characteristics, which results in high internal stresses and vulnerability to distortion and warpage of denture base. ${ }^{8}$

The injection molding technique was introduced by, Pryor in 1942 to overcome the adverse effects of compression molding. Many studies have demonstrated higher flexural and impact strengths for the injection molding technique compared to the conventional method. A constant flow of the resin from the sprue ensures compensation for the polymerization shrinkage and produces a more accurate denture compared to compression molding technique. ${ }^{9}$

The use of CAD/CAM dentures is changing the face of prosthodontic therapy for edentulous patients. CAD/CAM systems use a two-appointment technique whereby impressions, interocclusal records, and tooth selection can be completed in one appointment. Therefore, CAD/CAM processed dentures offer significant advantages to the dental practitioners and patient. The CAD/CAM dentures are machined from a pre-polymerized disc of acrylic resin material. This disc is produced under high pressure and heat, which eliminates the possibility of shrinkage, residual monomer content, and internal porosities of the definitive milled prosthesis. $^{10}$

There is limited literature regarding the CAD/CAM dentures and its mechanical properties. Hence, the purpose of this study was to evaluate its mechanical properties and compare it with the conventional and injection molding fabrication techniques. The primary research question is if there is any difference between the flexural and impact strength of the three denture base resins: CAD/ CAM PMMA, injection molded PMMA, and compression molded PMMA. The null hypothesis for this research is that there is no difference in the flexural and impact strengths of the test samples.

\section{Materials and Methods}

\section{Fabrication of Specimen}

The study was divided into three groups based on the manufacturing process of the dentures:

- Group I ( $n=30)$-control group; containing specimens fabricated by conventional compression molding technique;

- Group II $(n=30)$ —specimens fabricated using injection molding technique;

- Group III ( $n=30$ ) - specimens fabricated using CAD/CAM technology.

A metallic rectangular strip of $65 \mathrm{~mm} \times 10 \mathrm{~mm} \times 3 \mathrm{~mm}$ dimensions was milled and fabricated for the preparation of stone mold in a dental flask.

Group I: Samples were prepared using conventional heat curing PMMA denture base resin [polymer and monomer-powder and liquid (DPI, Mumbai, India)] according to the manufacturer's instructions ( $4.4 \mathrm{~mL}$ of monomer, $10 \mathrm{~g}$ of powder; weighing scale from Seco Shindhe Scale.CO., Pune, India). When the mixture reached the dough state (usually 5-10 minutes, depending on the room temperature), the dough was collected and packed well into the rectangular prepared mold by a routine procedure including the trial packing. Bench curing was done for 30 minutes. The PMMA heat cure resin was processed by a short curing cycle according to the manufacturer's recommendation. After bench cooling for 30 minutes, the flasks were immersed in the cold water until they were cooled to room temperature and deflasking was done.

Group II: Pre-proportioned capsules of resin and monomer (SR, Ivocap High Impact, Ivoclar Vivadent, Liechtenstein) were combined and loaded in the cap vibrator (Ivoclar Vivadent) for 5 minutes. The flask halves were clamped in the frame under $6,000 \mathrm{lbs}$ of pressure and the mixed capsule was inserted. This assembly was connected to a compressed air supply ( $6 \mathrm{bar} / 85 \mathrm{psi}$ ) to enable the plunger to descend and push the material into the mold. Total injection time was programmed to ten minutes, at room temperature. The apparatus was then placed in the polymerization bath for 35 minutes under an appropriate level of boiling water. After removal it was flash cooled, maintaining the pressure for 30 minutes.

Group III: CAD/CAM PMMA discs (Bloomden ${ }^{\text {TM }}$, China) of $98 \mathrm{~mm}$ diameter and $25 \mathrm{~mm}$ height were scanned in the DC5 milling system (Dental Concept Systems GmbH, Ulm, Germany). A layout of the strip of $65 \mathrm{~mm} \times 10 \mathrm{~mm} \times 3 \mathrm{~mm}$ dimensions was designed on the CAD file. The 5 -axis milling system was used to mill these blocks. The 4 th axis in this system can pivot $\pm 32^{\circ}$, while the 5 th axis rotates $360^{\circ}$. Both these axes are controlled by precision harmonic drive systems, which allows ultimate milling stability and accuracy of the discs. It consists of a visual progress indicator which indicates the stages and progress of the milling process with multi-colored interior LED lighting. An automated suction port was placed in the center of the operation, which ensured consistent vacuum performance.

Samples with frank defects and not fulfilling dimensional specifications were discarded and new samples were fabricated. Finishing of all the specimens was done with tungsten carbide bur and polished using the conventional laboratory polishing method: coarse pumice, water, lathe bristle brush, and soft leather polishing wheel. The finished and polished specimens were stored for wet conditions in distilled water at room temperature for 50 hours. Each specimen was measured with a digital Vernier caliper and the excess was trimmed. All specimens after finishing were stored at room temperature. A total of 30 specimens were prepared in each group, which were further subdivided into two subgroups of 15 specimens each for testing for flexural and impact strength.

\section{Testing of Specimen}

The values for flexural strength of each specimen was measured in a three-point bending mode using a Universal testing machine (UNITEST-10, ACME Engineers, India) at a crosshead speed of $5 \mathrm{~mm} /$ minute. The span of the two supports was $50 \mathrm{~mm}$. The flexural strength was calculated by a program in the universal testing machine (Fig. 1).

The flexural strength $(\sigma)$ was calculated using the following formula:

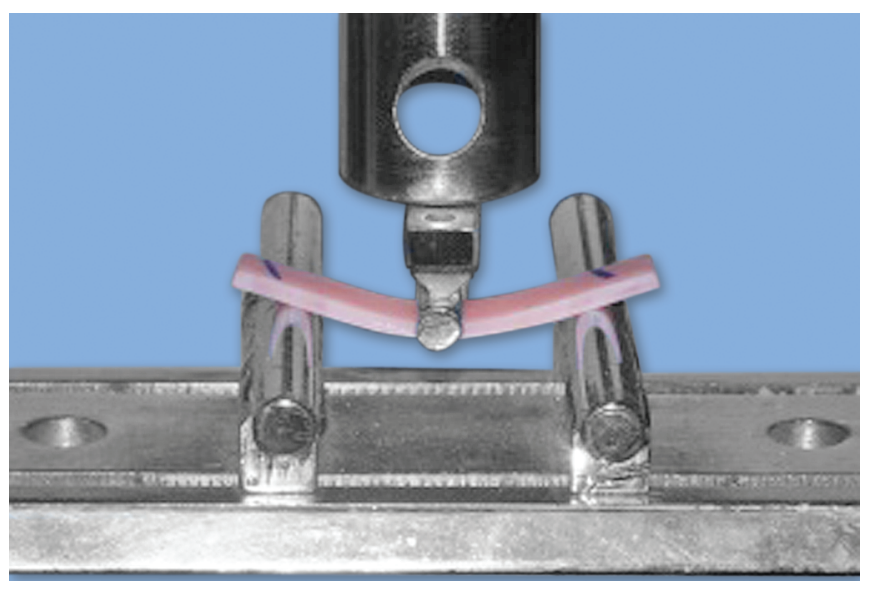

Fig. 1: Measurement of flexural strength using universal testing machine 


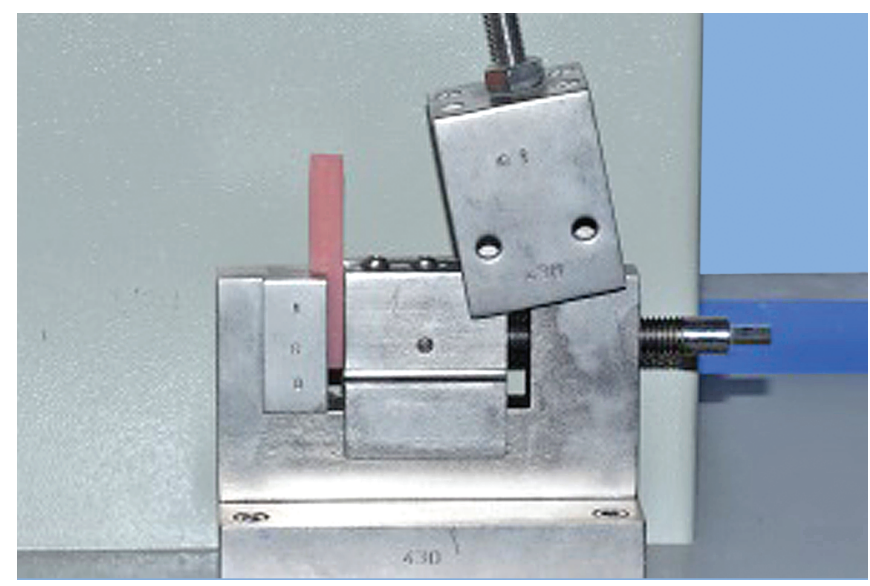

Fig. 2: Measurement of impact strength using Izod impact testing machine

$$
\sigma=3 F I / 2 b h^{2}
$$

where $F$ is the maximum load $(\mathrm{N})$ applied at the highest point of the stress-strain curve, $I$ is the span length $(\mathrm{mm}), b$ is the width of the test specimen $(\mathrm{mm}), h$ is the thickness of the test specimen $(\mathrm{mm})$.

Impact strength testing of the samples was done on the Izod impact testing machine with a pendulum of S2 scale in air at $23 \pm$ $2^{\circ} \mathrm{C}$. Before testing, the pendulum was released to freely swing in the air to record the air resistance (AR) encountered by the freeswinging pendulum. Air resistance of 0.6 Joules was recorded. The readings were taken on the $\mathrm{S} 2$ scale where the pointer was stabilized after swing. The specimen was clamped in position precisely. The pendulum was released and reading indicating energy absorbed (EA) to break the specimens on the S2 scale was recorded. All the specimens were tested in the same manner (Fig. 2).

Impact strength of the specimen was calculated by using the formula:

$$
\text { Impact strength }=U / a(b-\varepsilon)
$$

where, $a$ is the width of the specimen, $b$ is the thickness of the specimen and $\varepsilon$ is the depth of the notch $=0$

\section{Statistical Analysis}

Data obtained were compiled on an MS Office Excel sheet (Microsoft Office version 2013, Redmond Washington, USA) and subjected to statistical analysis using Statistical Package for Social Sciences (SPSS version 21.0 IBM Corporation, New York, USA). The mean values for the flexural and impact strength of the samples were calculated by the one-way ANOVA test. Intergroup comparison was done using Tukey pairwise comparisons (Tukey simultaneous tests for differences of means).

\section{Results}

A total of 90 specimens were prepared and evaluated for flexural and impact strength ( 15 samples per group for each test). The mean values of the flexural strength of all the samples were calculated by the one-way ANOVA (Table 1). All $p$ values $<0.05$ were considered statistically significant. The mean flexural strength of control group was $(74.70 \pm 5.02 \mathrm{MPa}$ ) which was significantly different from the mean values of the injection molding group $(84.82 \pm 5.30 \mathrm{MPa})$ and CAD/CAM samples $(93.16 \pm 5.46 \mathrm{MPa})$. Similarly, the mean values of the impact strength (Table 1) of all the samples were calculated by one-way ANOVA. The mean impact strength of the control group was $\left(8.446 \pm 0.937 \mathrm{~kJ} / \mathrm{m}^{2}\right)$, which was significantly different from the mean values of the injection molding group $\left(12.511 \pm 2.908 \mathrm{~kJ} / \mathrm{m}^{2}\right)$ and CAD/CAM samples $\left(15.625 \pm 2.512 \mathrm{~kJ} / \mathrm{m}^{2}\right)$.

The intergroup comparison was done using Tukey pairwise Comparisons (Tukey simultaneous tests for differences of means) as shown in Table 2. A statistically significant difference exists between the CAD/CAM group and injection molded samples $(p=0.000)$. Similarly, the intergroup comparison for impact strength was done using Tukey pairwise. It was also noted that a statistically significant difference existed between the CAD/CAM group and injection molded group ( $p=0.000)$.

\section{Discussion}

Polymethacrylate (PMMA) satisfies most of the requirements of denture base materials in terms of good aesthetics, ease of processing and reparability, reasonable cost, etc. However, it has relatively poor resistance to impact and flexural forces that may affect denture design and longevity. ${ }^{11,12}$ The inferior material property is attributed to the dimensional distortion and processing error that occurs during the compression molding technique of fabrication. ${ }^{12}$ To overcome these drawbacks, newer processing techniques have been developed. Injection molding technique has become a popular method of denture processing and the literature shows superiority in mechanical properties of these denture bases compared to conventional pressure pack technique. ${ }^{13}$

The superior mechanical properties and clinical popularity of SR-Ivocap as compared to other conventional denture base materials, is the primary reason why it was included as a test sample in this study. ${ }^{13-15}$ Digital advancements in denture fabrication and the CAD/ CAM dentures have become a rapidly expanding part of the dental market for rehabilitating edentulous jaws. ${ }^{16}$ However, not many studies have compared CAD/CAM denture bases to injection molded denture bases. Also, its impact strength has not been evaluated in the existing literature. Therefore, this study primarily focuses on the comparison of flexural and impact strengths of the CAD/CAM, injection molded and conventional compression molded denture base materials. ${ }^{17}$ The mean flexural strength was recorded with a universal testing machine. Three-point bending test is a routinely used and widely accepted test for assessment of flexural properties, according to the international standards for polymer materials and ISO 20795-1 for denture base polymers. ${ }^{18}$ The standard states that a minimum of $65 \mathrm{MPa}$ is the desired flexural strength of denture acrylics. ${ }^{18}$ By using that criterion, all groups in the present study have acceptable flexural properties for clinical use.

The mean impact strength in this study was recorded with an Izod impact tester for the three test groups. Impact strength data and fracture characteristics depend upon many factors including material selection, the geometry of the specimen, fabrication variables, stress concentrations, and position of specimen and temperature. Stress concentration are the main contributors to impact failure in dentures which include notches, cuts, depressions, sharp corners and grooves, rough or textured surfaces, or inclusion of foreign particles. ${ }^{19}$

The results demonstrated significant differences in flexural strength and impact strength amongst the three groups $(p<0.05)$; therefore, in disagreement with the null hypothesis. Pacquet et al. compared the variation in physical properties of denture polymers fabricated with different techniques. ${ }^{20}$ The outcomes of their study 
Flexural and Impact Strength of Two Conventional Denture Base Resins

Table 1: One way ANOVA (analysis of variance) for mean values of flexural and impact strength of test samples

\begin{tabular}{|c|c|c|c|c|c|c|c|}
\hline \multirow[b]{2}{*}{ Sr. no. } & \multirow[b]{2}{*}{ Group } & \multicolumn{3}{|c|}{ Flexural strength $(\mathrm{MPa})$} & \multicolumn{3}{|c|}{ Impact strength $\left(\mathrm{kJ} / \mathrm{m}^{2}\right)$} \\
\hline & & Mean & $\begin{array}{l}\text { Standard deviation } \\
\text { (SD) }\end{array}$ & $\begin{array}{l}\text { 95\% confidence } \\
\text { interval (CI) }\end{array}$ & Mean & $\begin{array}{l}\text { Standard deviation } \\
\text { (SD) }\end{array}$ & $\begin{array}{l}95 \% \text { confidence } \\
\text { interval }(\mathrm{Cl})\end{array}$ \\
\hline 1 & Group I-control & 74.70 & 5.02 & $(71.86,77.53)$ & 8.446 & 0.937 & $(7.488,9.404)$ \\
\hline 2 & $\begin{array}{l}\text { Group II-injection } \\
\text { molding }\end{array}$ & 84.82 & 5.30 & $(81.99,87.65)$ & 12.684 & 2.924 & $(11.725,13.642)$ \\
\hline 3 & Group III-CAD CAM & 93.16 & 5.46 & $(90.33,95.99)$ & 15.625 & 2.512 & $(14.667,16.584)$ \\
\hline
\end{tabular}

Table 2: Tukey pairwise comparisons for flexural strengths $(\mathrm{mPa})$ and impact strengths of test samples $\left(\mathrm{kJ} / \mathrm{m}^{2}\right)$ (Tukey simultaneous tests for difference of means: intergroup comparisons)

\begin{tabular}{|c|c|c|c|c|c|c|}
\hline Sr. no. & Difference of levels & $\begin{array}{l}\text { Difference of } \\
\text { means }\end{array}$ & SE of difference & $95 \% \mathrm{Cl}$ & $t$ value & Adjusted $p$ value \\
\hline \multicolumn{7}{|c|}{ Flexural strength } \\
\hline 1 & Control-CAD CAM & -18.46 & 2.01 & $(-24.08,-12.84)$ & -9.20 & 0.000 \\
\hline 2 & Injection molding-CAD CAM & -8.34 & 2.01 & $(-13.96,-2.72)$ & -4.16 & 0.000 \\
\hline 3 & Injection molding—control & 10.12 & 2.01 & $(4.50,15.74)$ & 5.04 & 0.000 \\
\hline \multicolumn{7}{|c|}{ Impact strength } \\
\hline 1 & Control-CAD CAM & -7.179 & 0.680 & $(-9.082,-5.276)$ & -10.56 & 0.000 \\
\hline 2 & Injection molding-CAD CAM & -2.941 & 0.680 & $(-4.844,-1.038)$ & -4.33 & 0.000 \\
\hline 3 & Injection molding—control & 4.238 & 0.680 & $(2.335,6.141)$ & 6.24 & 0.000 \\
\hline
\end{tabular}

and the present study are identical for the range of flexural strength of the CAD/CAM and injection molding technique PMMA. The observations of this study are also in agreement with Aguirre et al. and Al-Dwairi et al., who also found superior flexural and impact properties of the CAD/CAM resins compared to the conventional technique. ${ }^{17,21}$ The latter concluded that the CAD/CAM PMMA is more durable, as confirmed by scanning electron microscopy. ${ }^{21}$

Various reasons can be put forth for the differences in results of test samples such as residual monomer content, degree of conversion/polymerization, particle size, density, chemical nature of the polymer, etc. The residual monomer can influence the flexural strength of denture bases due to its plasticizing properties. ${ }^{9}$ Given this concept and the high flexural strength of injection molded specimens in this study, it may be concluded that in these specimens, the amount of residual monomer was less than that in the conventional processing technique and the polymerization was more complete. Also, the good physical and mechanical properties of the injection molded resin might be attributed to dual polymerization and small particle sizes. ${ }^{22}$

The higher flexural and impact strength values of the CAD/ CAM samples in the present study may be correlated to the higher degree of polymerization, which is one of the major factors determining resin strength. ${ }^{23}$ Since, the CAD/CAM resin blocks are pre-polymerized to a very high degree using equipment more sophisticated than conventional methods, a highly condensed resin mass with minimal porosities is achieved. Conversely, this is why autopolymerizing resins exhibit decreased strength and density, and higher porosities. Different compositions of the polymer and monomers also contribute to differences in flexural and impact strength. Resins that claim to be "high impact" may disperse rubbery comonomers such as butyl acrylate leading to higher impact strength. The injection molded material used in the current study claims to be a high impact. These resins, being more flexible due to the rubbery matrix; may negatively affect the flexural strength at the expense of increased impact strength. ${ }^{23}$
The current study clearly shows that the CAD/CAM denture bases have the highest flexural and impact strength of all test groups. Their clinical performance should provide an edge over all the other denture base materials and should be a clinician's first choice of material and processing technique for denture fabrication. However, the assessment of maxillomandibular relationships with CAD/CAM dentures is compromised. Also, the laboratory setup expenditure and feasibility is still a challenge in our daily practice. Some of these disadvantages may necessitate remaking the complete denture at a cost of additional time and expense. Among denture processing methods, injection molding has always been interesting for researchers because of the compensation of polymerization shrinkage due to the pressure exerted by injection of the acrylic resin. ${ }^{24}$ Since the feasibility of this technique is higher than CAD/CAM, it is widely preferred and commonly recommended by clinicians in the day-to-day practice. Moreover, the results of this study show that the physical properties of injection molded denture bases are closely comparable to CAD/CAM and therefore can be advocated for routine use over the compression molded dentures, where the CAD/CAM denture bases may not be possible.

The limitations of the current study were the in vitro nature of the study and the samples prepared do not replicate the shape of an actual denture.

\section{Conclusion}

Within the limitations of the study, it can be concluded that the CAD/CAM denture bases have the highest flexural and impact strength as compared to all the test groups. Moreover, the injection molding improves the flexural and impact strength of denture bases compared to the conventional PMMA.

\section{References}

1. Zarb GA, Hobkirk J, Eckert S, et al. Prosthodontic treatment for edentulous patients-e-book: complete dentures and implantsupported prostheses. Elsevier Health Sciences; 2013. p. 452. 
2. Peyton FA. History of resins in dentistry. Dent Clin North Am 1975;19(2):211-222.

3. John J, Gangadhar SA, Shah I. Flexural strength of heat-polymerized poly(methyl methacrylate) denture resin reinforced with glass, aramid, or nylon fibers. J Prosthet Dent 2001;86(4):424-427. DOI: 10.1067/mpr.2001.118564.

4. Singh S, Palaskar JN, Mittal S. Comparative evaluation of surface porosities in conventional heat polymerized acrylic resin cured by water bath and microwave energy with microwavable acrylic resin cured by microwave energy. Contemp Clin Dent 2013;4(2):147-151. DOI: 10.4103/0976-237X.114844.

5. Kanie T, Arikawa H, Fujii K, et al. Mechanical properties of reinforced denture base resin. Dent Mater J 2002;21(3):261-269. DOI: 10.4012/ dmj.21.261.

6. Stafford GD, Huggett R, MacGregor AR, et al. The use of nylon as a denture base material. J Dent 1986;14(1):18-22. DOI: 10.1016/03005712(86)90097-7.

7. Vallittu PK. A review of fiber-reinforced denture base resins. J Prosthodont 1996;5(4):270-276. DOI: 10.1111/j.1532-849X.1996. tb00511.x.

8. Acosta-Torres LS, Mendieta I, Nuñez-Anita RE, et al. Cytocompatible antifungal acrylic resin containing silver nanoparticles for dentures. Int J Nanomedicine 2012;7:4777-4786. DOI: 10.2147/ IJN.S32391.

9. Gharechahi J, Asadzadeh N, Shahabian F, et al. Flexural strength of acrylic resin denture bases processed by two different methods. J Dent Res Dent Clin Dent Prospect 2014;8(3):148. DOI: 10.5681/ joddd.2014.027.

10. Infante L, Yilmaz B, McGlumphy E, et al. Fabricating complete dentures with CAD/CAM technology. J Prosthet Dent 2014;111(5):351-355. DOI: 10.1016/j.prosdent.2013.10.014.

11. Hargreaves AS. Polymethylmethacrylate as a denture base material in service. J Oral Rehabil 1975;2(1):97-104. DOI: 10.1111/j.1365-2842.1975. tb00913.x.

12. O'Brien WJ. Dental materials and their selection. 2 nd ed., Chicago(IL): Quintessence Pub; 1997. pp. 85-86.

13. Ganzarolli SM, Nunes De Mello JA, Shinkai RS, et al. Internal adaptation and some physical properties of methacrylate based denture base resin polymerized by different techniques. J Biomed Mater Res 2007;82(1):169-173. DOI: 10.1002/jbm.b.30718.

14. Hamanaka I, Takahashi Y, Shimizu H. Mechanical properties of injection-moulded thermoplastic denture base resins. Acta Odontol Scand 2011;69(2):75-79. DOI: 10.3109/00016357.2010.517557.

15. Uzun G, Hersek N. Comparison of the fracture resistance of six denture base acrylic resins. J Biomater Appl 2002;17(1):19-29. DOI: 10.1177/0885328202017001597.

16. Chittaranjan B, Taruna M, Sudheer N, et al. Evaluation of shear bond strength of three different types of artificial teeth to heat cure denture base resin: an in vitro study. Indian J Dent Res 2013;24(3):321-325. DOI: 10.4103/0970-9290.117994.

17. Aguirre $\mathrm{BC}$, Chen JH, Kontogiorgos ED, et al. Flexural strength of denture base acrylic resins processed by conventional and CADCAM methods. J Prosthet Dent 2020;123(4):641-646. DOI: 10.1016/j. prosdent.2019.03.010.

18. ADA. ANSI/ADA Standard No. 139 (ISO 20795-1), Denture Base Polymers. American Dental Association; 2013.

19. Harrison A, Huggett R. Effect of the curing cycle on residual monomer levels of acrylic resin denture base polymers. J Dent 1992;20(6):370374. DOI: 10.1016/0300-5712(92)90031-7.

20. Pacquet $W$, Benoit $A$, Hatège-Kimana $C$, et al. Mechanical properties of CAD/CAM denture base resins. Int J Prosthodont 2019;32(1):104-106. DOI: 10.11607/ijp.6025.

21. Al-Dwairi ZN, Tahboub KY, Baba NZ, et al. A comparison of the flexural and impact strengths and flexural modulus of CAD/CAM and conventional heat-cured polymethyl methacrylate (PMMA). J Prosthodont 2020;29(4):341-349. DOI: 10.1111/jopr.12926.

22. Vallittu PK, Lassila VP. Effect of metal strengthener's surface roughness on fracture resistance of acrylic denture base material. J Oral Rehabil 1992;19(4):385-391. DOI: 10.1111/j.1365-2842.1992.tb01580.x.

23. Bidra AS, Taylor TD, Agar JR. Computer-aided technology for fabricating complete dentures: systematic review of historical background, current status, and future perspectives. J Prosthet Dent 2013;109(6):361-366. DOI: 10.1016/S0022-3913(13)60318-2.

24. Solnit GS. The effect of methyl methacrylate reinforcement with silane treated and untreated glass fibres. J Prosthet Dent 1991;66(3):310-314. DOI: 10.1016/0022-3913(91)90255-U. 